\section{Chemistry on Tape}

The British and American Chemical Societies have been holding joint meetings in London and Nottingham to provide British chemists-and a good many people from other specialisms as well-with first hand experience of the advantages and the difficulties of using information stored on magnetic tape. As at the best sales conventions, description of what is available was accompanied by practical demonstrations in which inquisitive chemists did their best to pose questions the machines would find it difficult to answer. At one point in the London meeting it looked as if a man concerned with the metabolism of tryptophan derivatives was hoping that the machine would not merely say what had been done already, but would also suggest what to do next and how to do it.

In practice, the demonstrations were at once a hint of the useful things that may one day be possible, and a proof that it will be a long time before they are all realities. The officials of the American Chemical Society were most of all concerned to show in operation two of the new services available from the Chemical Abstracts Service-a list of titles culled from 690 chemical journals and sold as Chemical Titles, and a similar compilation of titles and summaries from 550 journals which is called Chemical-Biological Activities. The notion is that the lists can be scanned by a computer for the occurrence of words or parts of words specified by the user. Chemical compounds can be described by molecular formulae or even by the code numbers being introduced by the American Chemical Society as unambiguous means of referring to chemicals. At the practical demonstrations, most of the time was spent on the subtleties of how to ask meaningful questions of the literature.

As things are, a would-be user has to anticipate the ways in which machines are wooden headed. Mr. Philip K. Reily of Chemical Abstracts explained at the London demonstration how a man looking for recently published articles on air pollution would have to remember that the word "contamination" frequently crops up instead of "pollution". Eventually, no doubt, computer programmes will choose alternative words for themselves, but for the time being people must construct their own equivalents as they go along. (Chemical Abstracts is hoping to be of some help by publishing lists of related words based on the usages of the chemical literature.) As things are, it is even necessary to keep in mind that there is more than one way of spelling the word "sulphur". But the real difficulty in asking an intelligent question is to be clear what it would be good to know, and then to ask for a list of titles or summaries by specifying a subject which is neither so specific that it is unlikely that the file will have anything to say nor so general that the computer will respond by printing most of what is on the tape.

These niceties suggest that organizations using the tapes will interpose an information specialist between a scientist and the computer. The time spent on searching-when the computer reads through the whole of its file-implies that it will be most economical to deal with requests for information in batches. This in turn suggests a centralized and somewhat formal process, with routine searches of the lists of titles as they are issued every two weeks, but it is agreed that things will be different if, in due course, multiple access computers come into their own. For the time being, however, the use made of the American system in British conditions is to be studied closely at the University of Nottingham as part of a joint project between the Chemical Society and the Office of Scientific and Technical Information. Dr. A. K. Kent, who will be in charge of the operation, was available at the public demonstrations to explain how he will be studying not merely the use made of the new system but the effect of this on traditional patterns of library usage.

\section{Money for the R.I.}

THE prospect of the Royal Institution appealing for money comes as something of a shock-but it will be necessary if the ambitious plans put forward by the new resident professor, Dr. George Porter, are to be realized. The splendid Vulliami façade in Albemarle Street presents an image of wealth and influence which reached its peak in the middle of the nineteenth century, but if the Institution is to expand as Professor Porter wishes, its own resources will be quite inadequate. No doubt the Institution could maintain its present activities without any financial embarrassment - the research into photo-chemistry by Professor Porter and into metal physics by Professor R. King is in no danger-but, like the British Association for the Advancement of Science, it is the educational facilities which need an injection of new capital if they are to survive and expand. Professor Porter hopes that far more children will be able to visit the Institution for lectures, and also that lecturers should visit the schools so as to take the evangelizing part of the Institution's work into the classrooms. Television and films will have a part to play in this development, and it is hoped that the filming and recording of scientists who visit the Institution to give lectures will supply archival material which has never before been available. The most exciting prospect, however, is the hope of restoring to its original condition the laboratory where Faraday carried out his work. Faraday's apparatus and notebooks, together with those of Davy, Tyndall, Dewar and Bragg, are preserved at the Royal Institution, and this seems an ideal opportunity to display them to the general public. This project represents only a small fraction of the total investment needed, but it may well serve as a peg on which to hang the rest of the appeal.

\section{Scientific Promotions}

"Special merit" promotions have been awarded to twenty-nine Government research scientists as a result of the recommendations of the special committee which annually reviews the work of scientists in Government and other public service establishments. These promotions to a higher grade do not carry the additional administrative burden normally associated with the new grade, and so enable the scientists to continue their research work. The promotions-to grades broadly comparable with the rank of university professor or reader-have this year for the first time included scientists not in the Scientific Officer class, but who are doing comparable work. The full list of those promoted follows:

Dr. J. S. Hey (Royal Radar Establishment, Malvern), Mr. G. F. Clarke (Royal Aircraft Establishment, 